Tension of the Globe of the Eye in Man and Animals, and on the Physiological Influence on this Tension of such Substances as Atropia, Daturin, Eserine, and Pilocarpine

Dr. C. R. A. Wright, St. Mary's Hospital, Paddington__ For Continuation of Researches on certain Points in Chemical Dynamics; on the Determination of Chemical Affinity in Terms of Electrical Magnitudes; and on some of the lesserknown Alkaloids

Prof Schorlemmer, Owens College, Manchester.-For C̈ $\ldots$ tion of Researches into (I) the Normal Paraffins, (2) Suberone, (3) Aurin $\ldots \begin{array}{lllllllllll}\ldots & \ldots & \ldots & \ldots & \ldots & \ldots & \ldots & \ldots & \ldots & € 150\end{array}$ W. N Hartley. King's College, Strand.-For Investigation of the Fluid Contents of Mineral Cavities; of the Properties of the Phosohate of Cerium; of Methods of Estimating the Carb nic Acid in small Samples of Air ; and of Pbotographic Spectra

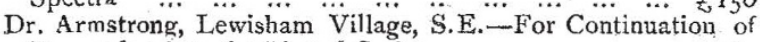
Researches into the Phenol Series...

\section{THE SOURCES OF LIGHT}

WHEN the sun rises in the morning, the darkness of the night seems to fade away, and, wherever we look, without or within, all the air and space about us appears to be full of light. When evening comes again, the daylight disappears, and the moon and the stars give us another light. In the house we start the lamps, and they give us another light. Out-of-doors, in the dusky meadows, we see the fire-flies darting about, and giving out pale sparkles of yellow light as they fly. We look to the north in the night and see the aurora, or we watch the lightnings flash from cloud to cloud, and again we see more light.

This light from sun and moon, the stars, the fire, the clouds, the sky, is well worth studying. It will give us a number of the most beautiful and interesting experiments, and by the aid of a lamp, or the light of the sun, we can learn much that is both strange and curious, and perhaps exhibit to our friends a number of charming pictures, groups of colours, magical reflections, spectres, and shadows. All light comes from bodies on the earth or in the air, or from bodies outside of the atmosphere ; and these bodies we call the sources of light. Light from sources outside of the atmosphere we call celestial-light, and the sources of this light are stars, comets, and nebulæ. The nebulæe appear like flakes and clouds of light in the sky, and the comets appear only at rare intervals, as wandering stars that shine for a little while in the sky and then disappear. The stars are scattered widely apart through the vast spaces of the universe, and they give out their light both day and night. The brightest of these stars is the sun. When it shines upon us, the other stars appear to be lost in the brighter light of this greater star, and we cannot see them. At night, when the sun is hid, these other stars appear. We look up into the sky and see thousands of them, fixed points of light, each a sun, but so far away that they seem mere spots and points of light. Besides these stars are others, called the planets, that move round the sun. These give no light of their own, and we can only see them by the reflected light of the great star in the centre of our solar system. Among these stars are the Moon, Venus, Mars, Jupiter, and many others. We might call celestial light starlight; but the light from the great star, the sun, is so much brighter than the light of the others, that we call the light it gives us sunlight, and the light from the other suns we call starlight. For convenience, we also call the reflected light from the planets starlight, and the 'light from our nearest planet we call moonlight.

Terrestrial flight includes all the light given out by things on the earth, or in the air that surrounds the earth.

"From a forthcoming volume of the "Nature Series"- "Light: a Series of Simple, Entertaining, and Inexpensive Experiments in the Phenomena of Light, for the Use of Students of Every Age," by Alfred M. Mayer and
The most common light we call firelight, or the light that that comes from combustion. When we light a lamp or candle, we start a curious chemical action that gives out light and heat. The result of this action is fire, and the light that comes from the flame is firelight. When a thunder-storm rises, we see the lightning leap from the clouds, and give out flashes of intensely bright light. Sometimes, at night, the northern sky is full of red or yellow light, darting up in dancing streamers, or resting in pale clouds in the dark sky. You have seen the tiny sparkles of light that spring from the cat's back when you stroke her fur in the dark, or have seen the sparks that leap from an electrical-machine. All these-the aurora, the lightning, and the electric sparks - are the same, and we call such light electric light.

Sometimes, in the night, we see shooting-stars flash across the sky. These are not stars, but masses of matter that, flying through space about the earth, strike our atmosphere and suddenly blaze with light. The friction with the air as they dart through it is so great that these masses glow with white heat, and give out brilliant light. Two smooth white flint pebbles, or two lumps of white sugar, if rubbed quickly together, will give out light, and this light we call the light from mechanical action.

Sailors upon the ocean sometimes see, at night, paleyellow gleams of light in the water. A fire-fiy or glowworm imprisoned under a glass will show, in the dark, bright spots of light on his body. A piece of salted fish or chip of decayed wood will sometimes give a pale, cold light in the night; and certain chemicals, like Bologna phosphorus and compounds of sulphur, lime, strontium, and barium, if placed in the sunlight in glass vessels and then taken into the clark, will give out dull-coloured lights. All these--the drops of fire in the sea, the glow-worm, the bit of decayed wood, and these chemicals-are sources of the light called phosphorescence.

These are the sources of light-the stars, the fire, electricity, friction, and phosphorescent substances. We can study the light from all of them, but the light from the sun or a lamp will be the most convenient. The light of the sun is the brightest and the cheapest light we can find, and is the best for our experiments. A good lamp is the next best thing, and in experimenting we will use either the sun or a lamp, as happens to be most easy and convenient.

\section{The Heliostat.}

In looking out of doors in the daytime we find that the sunlight fills all the air, and extends as far as we can see. It shines in at the window and fills the room. Even on a cloudy day, and in rooms where the sunshine cannot enter, the light fills everything, and is all about us on every side. Now, in studying light we do not wish a great quantity. We want only a slender beam, and we must bring it into a dark room, where we can see it and walk about it and examine it on every side, bend it, split it up into several beams, make it pass through glass or water, and do anything else that will illustrate the laws that govern it.

Choose a bright, sunny day, and go into a room having windows through which the sun shines. Close the shutters, curtains and blinds, at all the windows save one. At this window draw the curtain down till it nearly closes the window, and then cover this open space with a strip of thick wrapping-paper. Cut a hole in this paper about the size of a five-cent piece, and at once you will have a slender beam of sunlight entering the hole in the paper and falling on the floor. Close the upper part of the window with a thick shawl or blanket, and, when the room is perfectly dark, our slender beam of light will stand out clear, sharp, and bright.

As soon as we begin to study this beam of light, we find two little matters that may give us trouble. The sun does not stand still in the sky, and our beam of light 
keeps moving. Besides this, the beam is not level, and it is not in a convenient place. We want a horizontal beam of light, and some means of keeping it in one place all day. An instrument that will enable us to do this, and that can be adjusted to the position of the sun in the sky at all seasons of the year and every hour of the day, may be readily made, and will cost only a small sum of money.

We givể several drawings giving different views of such an instrument and some of its separate parts. It is called a heliostat, and we shall find it of the utmost value in our experimenting in light, heat, soun 1 , electricity, and other branches of physical science.
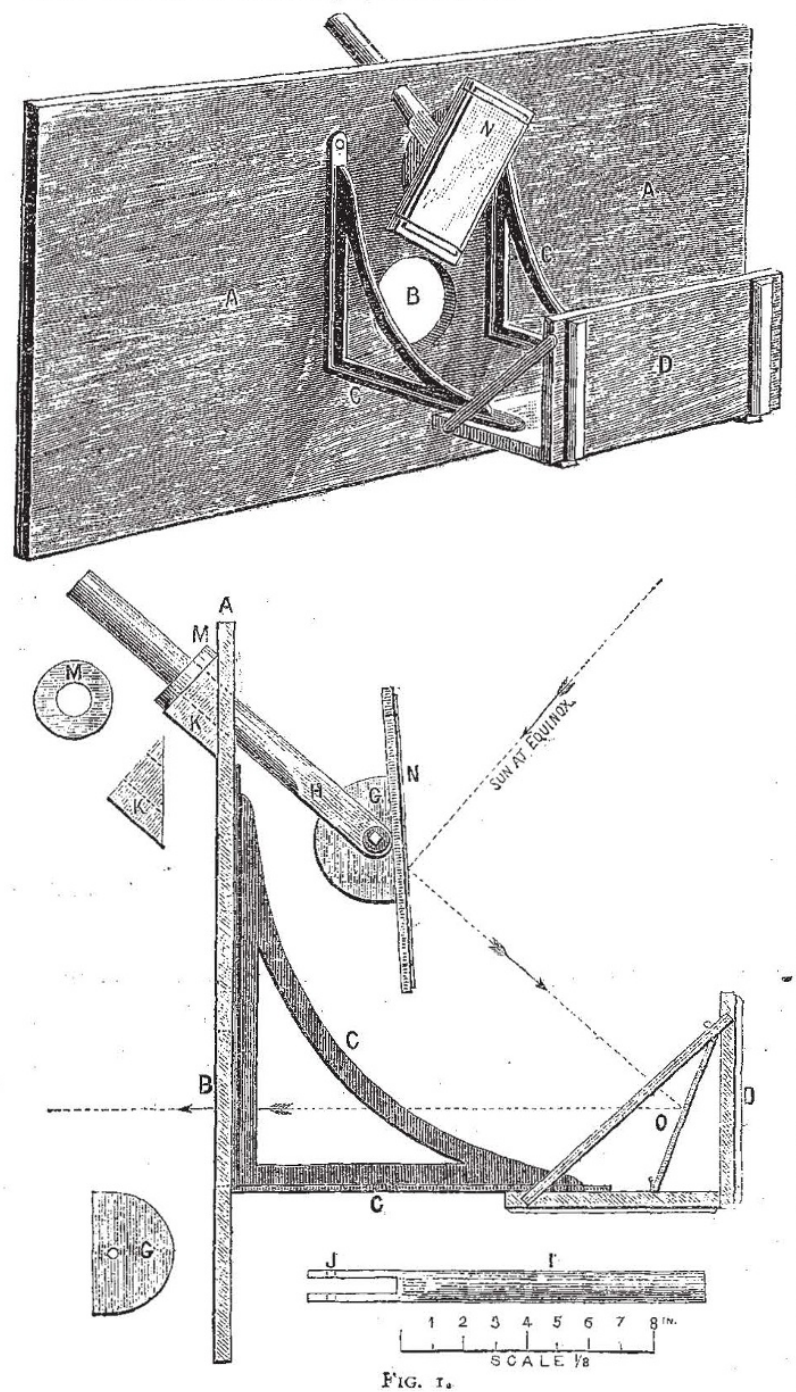

The first drawing represents a front-view of the heliostat. The second drawing gives an end-view, and we can now make one by simply following these few directions: The part marked $\mathrm{A}$ in the two drawings is a piece of pine board, 23 inches $(58.4$ centimetres) wide and two or more feet long, or as long as the window where it is to be used is wide. Any boy who can use plane and saw can make this piece of work out of common inch-board, and, if you have no pieces so wide as that, it can be made of two or more pieces fastened together with cleats; but, in this case, all the cracks must be close and tight. In the middle of this board, cut a round hole 5 inches ( $12 \%$ centimetres) in diameter, with its centre 8 inches from the bottom of the board. In the first drawing this hole can be seen at B, and in the second drawing it is shown by dotted lines at $B$. On one side of the board screw two iron brackets, using brackets measuring 14 inches ( $35^{\circ} 5$ centimetres) by 12 inches ( $30^{\circ} 5$ centimetres). These brackets are placed one on each side of the hole in the board, and are placed 14 inches $\left(35^{\circ} 5\right.$ centimetres) apart, and with the short arm of the bracket against the board. In the first drawing the two brackets are shown, and in the second drawing one is shown in profile, and they are marked $c$ in both drawings. On the end of the brackets is placed a flat piece of board, $6 \frac{1}{2}$ inches ( 16.5 centimetres) wide and 14 inches $(35.5$ centimetres) long, or long enotigh to reach from one bracket to the other. This board may be screwed up to the brackets, and thus make a shelf. Care must be taken in fastening this shelf to the brackets to place it so that the outside edge of the shelf will be 16 inches $\left(40^{\circ} 6\right.$ centimetres) from the large board. On the outside edge of this shelf another board, 7 inches (17.8 centimetres) wide, is placed upright, and secured with screws and smali strips of wood at the ends, as in the drawing. This shelf, with the wooden back, is marked $D$ in the drawings.

These things make the fixed parts of the heliostat, and we have next to make the movable parts, or the machinery whereby it can be adjusted to the movement of the sun in the heavens. First, get out a flat piece of board $10 \frac{1}{2}$ inches $\left(26^{\circ} 7\right.$ centimetres) long, $6 \frac{1}{4}$ inches ( 16 centimetres) wide, and $\frac{1}{2}$ inch ( 12 millimetres) thick. Then make a flat, half-round piece, shaped like the figure marked G. This piece must be $\frac{1}{4}$ inch ( 7 millimetres) thick, $5 \frac{1}{2}$ inches (I4 centimetres) along the straight side, and with the circular part with a radius of 3 inches $\left(7^{\circ} 6\right.$ centimetres). A hole, $\frac{1}{2}$ inch ( 12 millimetres) in diameter, is made in this, as represented in the drawing, and then the half-round piece must be screwed to the flat piece of wood we just cut out. In the part marked $\mathrm{N}$ in Fig. I you will see these two pieces fastened together. The piece marked $\mathrm{I}$ is the most difficult piece of all. It should be made of ash or some hard wood. One end is square, and has a deep slot cut in it; the rest is round, and may be $I_{2}^{\frac{1}{2}}$ inch $(32$ millimetres in diameter. The square part must be large enough to slip over the half-circular piece, $\mathrm{G}$, as is shown at $\mathrm{H}$. A hole, $\frac{1}{2}$ inch (12.millimetres) in diameter, is cut in the two ends, as marked by dotted lines at $y$, and through these holes an iron bolt and nut are fitted, so as to hold the circular piece, $G$, and yet allow it to turn freely in every direction. " $A$ hole, $1 \frac{1}{4}$ inch ( 32 millimetres) in diameter, is cut through the triangular piece of wood $\mathrm{K}$, as shown by the dotted lines, and then this block is securely fastened to the back of the large board, as shown in the second drawing. An opening of the same diameter, and having the same direction, is also cut through the board, and the movable piece, marked $\mathbf{I}$, is put through this hole, as in the drawing. Finally, we want a wooden washer, $3 \frac{1}{9}$ inches $(8.7$ centimetres) wide, as represented at M. This we slip over the long wooden handle; as shown in the second drawing, and this washer rests on the block $\mathrm{K}$, the top of which is $3 \frac{1}{2}$ inches square. This makes all the movable parts of the heliostat, and, when we have put in the mirrors, the instrument is finished and ready for use. We must have two mirrors, one 6 inches ( $15^{\circ} 2$ centimetres) square and one Io inches $\left(25^{\circ} 4\right.$ centimetres) long and 6 inches ( $15^{\circ} 2$ centimetres) wide. These may be made of common looking-glass : but plate-glass with silvered back is far better, and costs only a little more.

Ary carpenter can make this instrument, and the cost will be about as follows: Wood, 50 cents ; labour, $\$ 1.75$; glass, $\$ 1$; iron nut, 5 cents ; brackets, 50 cents-total, $\$ 3.80$. When finished, the instrument should have a coat of shellac-varnish, and, when this is done, the mirrors may be put in place, and fastened on with very heavy bands of rubber. This will enable us to take the glasses 
off when the instrument is not in use, and if the elastic bands or rings are very strong, they will answer perfectly. The long mirror is to go on the miovable piece at $\mathrm{N}$, and the small mirror stands on the shelf, facing the opening in the board, at 0 . This mirror stands at the angle shown in the next drawing (Fig. 2), and the other mirror is adjusted to the sun at its various positions in the sky at different seasons of the year.

Here is a diagram showing the position of the handle of the heliostat, and the mirror for different seasons and in different parts of the country. The handle must be placed on a line parallel with the axis of the earth, and the four dotted lines give its position when the heliostat is to be used in Boston, New York, Washington, and New Orleans. This also causes the block of wood marked $\mathrm{K}$ to have a slightly different shape, so that the hole through it will be in the middle. The dotted line marked "At Equinox" shows the path of the light from the sun, and

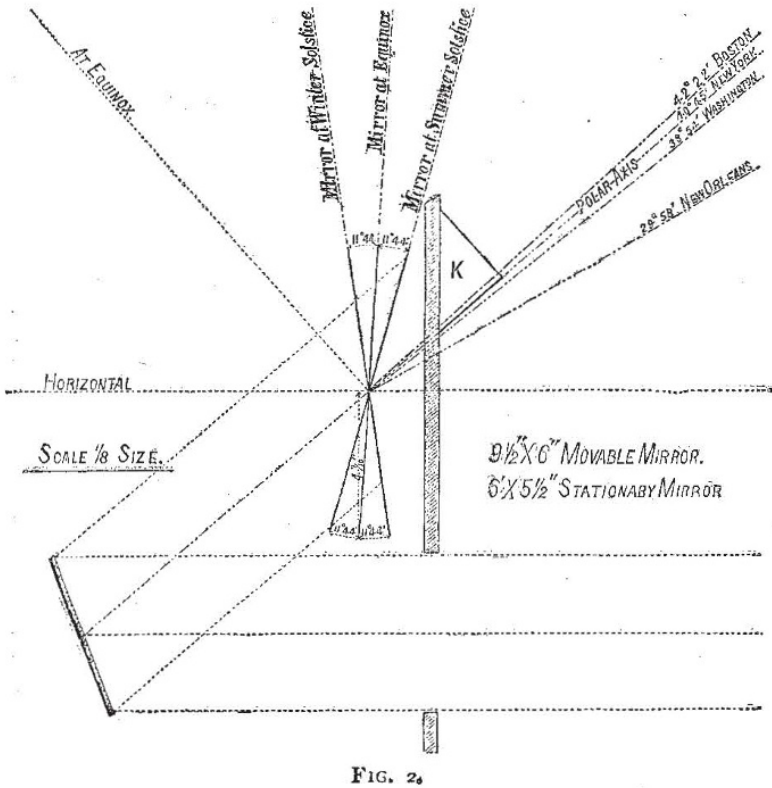

the three dotted lines show the paths of the reflected light as it passes from one mirror to the other. The position of the movable mirror is also shown in the positions it has at the summer and winter solstices.

\section{First Experiment with the Heliostat.}

Choose a bright sunny day, and take the heliostat into a room having a window facing the south. Raise the sash and place the instrument in the window, and fasten it there so that it will be firm and steady. Before closing the window down upon it, move the larger mirror on its axis till it reflects a beam of light into the small mirror. Then turn the handle to the right or left, and a round, horizontal beam of light will enter the room. When this is done, close all the windows, so as to make the room as dark as possible. To do this, shawls or blankets or enamelled cloth will be found useful inside the curtains and shutters. Then get a piece of cardboard, about 6 inches (I 5 '2 centimetres) square, and lay a five-cent piece in the centre, and, with a knife, cut a hole in the card just the size of the coin. Then fasten this, with pins or tacks, over the opening in the heliostat.

We have now a slender beam of light in a dark room. Walk about and study it from different sides. See how straight this slender bar of light is; it bends to neither the left nor the right, but extends across the room in an absolutely straight line. As the sun moves, turn the handle of the heliostat to keep the light in place.

Here (Fig. 3) is a picture of a dark room, in the window of which is the heliostat. In the centre of the piece of cardboard is the small hole where the light enters the room. A boy is holding one end of a long piece of linen thread just at the bottom of the hole in the card, and another boy has drawn the thread out straight and tight, so that it just touches the beam of light throughout its length.

Were you to try this experiment, you would see that the thread would suddenly be lighted up throughout its whole length, and would shine in the dark room like silver. Then if the boy allows the thread to become slack and loose, or if he lowers it even a very little, it will disappear in the darkness. If he raises and lowers it quickly, it will seem to appear and disappear as if by magic.

This is a very pretty experiment ; but we must not stop to look at its merely curious effects. Try it over several times, and see if it does not show you something about the beam of sunlight. Plainly, if the thread is lighted up its whole length when it is straight, then the beam of

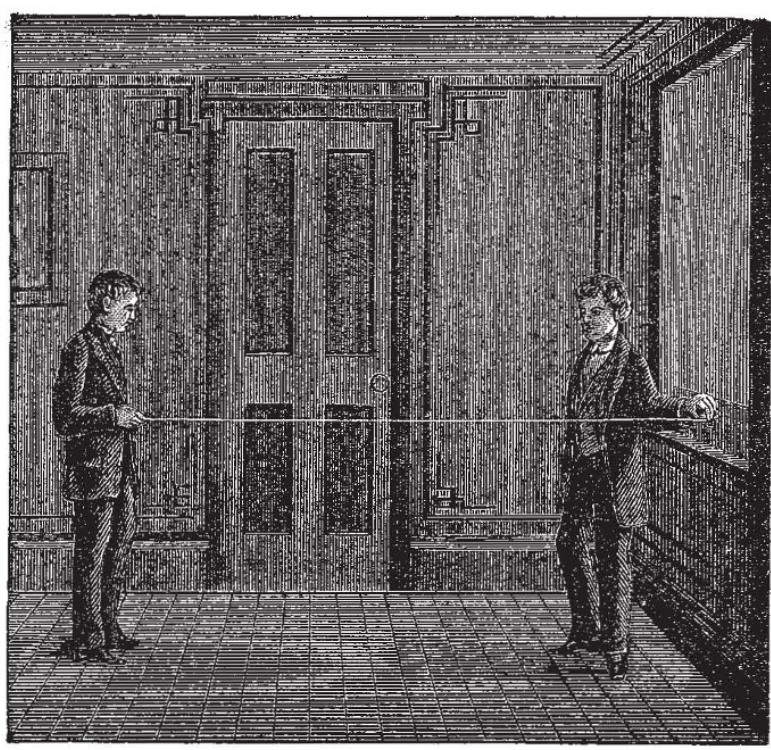

FiG. 3.

light must be straight also. Here we discover something about light; we learn that it has a certain property. Our experiment shows that light moves in straight lines.

\section{Experiment with Cards and a Lamp.}

Here (Fig. 4) is a picture representing three little wooden blocks placed in a row upon a flat, smooth table, and fastened to them are three postal-cards, so that they will stand upright. At the end of the table is a small lamp. This is all we need to perform another experiment, that will show us the same thing we observed with the beam of light from the heliostat. To make these things, get a piece of wood Io inches $\left(25^{\circ} 4\right.$ centimetres) long, 3 inches ( 76 millimetres) wide, and $\mathrm{I} \frac{1}{2}$ inch ( 37 millimetres) thick, and saw it into 5 pieces, each $2 \frac{1}{2}$ inches $(64$ millimetres) long. Next make three slips of pine, 4 inches (1o centimetres) long, 3 inches ( 76 millimetres) wide, and $\frac{1}{8}$ inch (4 millimetres) thick. Having made these, get three postal-cards, and lay them flat on a board, one over the other. Just here we need a tool for making small holes and doing other work in these experiments ; and we push, with a pair of pliers, a cambric needle into the end of a wooden penholder or other slender stick, putting the eye-end into the wood, and thus making a needle-pointed awl. Measure off one-half inch from one end of the top postal-card, and with the awl punch a hole through them all, just half-way from each side. Lift the cards up, and with a sharp penknife pare off the rough edges of the 
holes, and then run the needle through each, so as to make the holes clean and even.

Take one of these cards and one of the wooden slips, and put the card squarely on one of the woolen blocks and place the slip over it, and tack them both down to the block. This will give us the cards and blocks as shown in the picture. When each card is thus fastened to a block, we shall have two blocks left. These we can lay aside, as we shall need them in another experiment.

Now light the lamp, and place one block on the table, quite near the lamp. Look at the lamp carefully, and see that the flame is just on a level with the hole in the card. If it is too high or too low, place some books under it, or put the lamp on a pile of books on a chair near the table. Take a chair and sit at the opposite end of the table, and place another card before you. Now look, through the hole in this card, at the first card before the lamp. If the table is level, you will see a tiny star or point of light shining through the holes in the two cards. Without moving the eye, draw the third card into line between the others, and in a moment you will see the yellow star shining through all three cards.

Next take a piece of thread and stretch it against the sides of the three cards, just as they stand, and immediately you see that they are exactly in line. The holes in the cards we know are at the same distance from the edges of the cards, and our experiment proves that the beam of light that passed through all the holes must be straight,

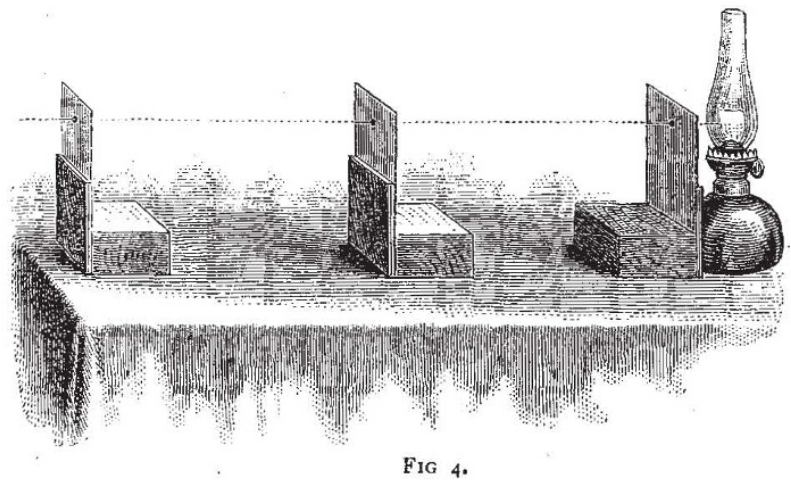

or we could not have seen it. The cards are in a straight line, and the beam of light must also be straight. This experiment, like the first, shows us that there is a law or rule governing the movement of light, and that law is, that light moves in straight lines.

Move the lamp as near to the edge of the table as possible, and then bring one of the cards close to the lamp chimney. Then change your seat, and repeat this experiment several times in different directions. Each time you will see exactly the same thing, no matter in what direction the light moves from the lamp. The lamp may be moved from one side of the table to the other, and in every direction we shall find the light moving in exactly straight lines from the source of light. This is true whether the source be the sun, a lamp, or a star. One can walk all about the lamp and see it from every side, and we can place our three cards in any direction, north or south, up or down, east or west, or in any and every direction, and every time it will give the same result.

Thus we have found out the law by which light moves, viz., it moves in straight lines in all directions from the source of light.

Knowing this, you can readily think of a number of things in which these laws are made useful. A farmer planting an orchard, an astronomer fixing the positions of stars, a sailor steering his ship by night, employs this law: the first, to arrange his trees in straight lines; the second, to measure out vast angles in the sky; and the third, to lay the courses of his ship in safety. Each employs these laws with certainty and safety, because they are fixed and never change.

\section{OUR ASTRONOMICAL COLUMN}

DOUble StARS.-Vol. xliii. of the Memoirs of the Royal Astronomical Society contains two series of micrometrical measures of double stars. The first, by Mr. Knott, includes measures taken near Cuckfield, Sussex, between the years 1860 and 1873 , with a refractor by Alvan Clark, having an aperture of $7 \frac{1}{3}$ inches, one of the instruments formerly in the possession of the Rev. W. R. Dawes. Measures of most of the well-known binaries will be found in this series, as also of a number of objects not so frequently under observation. Amongst the latter is the suspected variable, $U$ Tauri, which has been observed on several occasions since November, $1_{8} 86_{3}$; D'Arrest first pointed out that this star, supposed to be variable by $\mathrm{Mr}$. Baxendell, is really double ; it is included in Schönfeld's last catalogue of suspicious objects with the query, "welche Componente veränderlich?" Mr. Knott's observations throw no light on this point, as he appears to have failed to notice any certain traces of change. A note referring to a star near $\beta$ Leonis deserves attention. Smyth, in his Cycle of Celestial Objects, gives a measure, or, as it should perhaps be termed, an estimation of the position of a companion to this bright star, which he calls an eighth magnitude, and dull red, position I I $4^{\circ}$, distance $298^{\prime \prime}$. At the epoch 1864.38 there was no star of such magnitude in this place, but Mr. Knot measured one which by the method of limiting apertures was found to be rI $6 \mathrm{~m}$., position $115^{\circ} 4$, distance $303^{\prime \prime} \cdot 5$. The inference, especially in presence of Smyth's judg. ment of the colour of his companion, must be that we have here a new variable star. The Durchmusterung has nothing in this position.

The other series of double star measures to which we have referred emanates from the Temple Observatory, Rugby, and forms the second catalogue issued by Mr. Wilson and Mr. Seabroke. The previous catalogue was printed in the preceding volume of the Memoirs, and contains some introductory remarks that are wanting in the present one. The selection of objects and the instrumental means appear to be the same; the stars are found either in the Dorpat Catalogue or in the Pulkowa Catalogue of 1850. Amongst them may be noted O.s. 298, the first measures of which by the discoverer yave, for $1846^{*} 49$, position $183^{\circ} \cdot 8$, distance $I^{\prime \prime} \cdot 19$, while the Temple Observatory measures, $1873^{\circ} 48$, assign for the position $232^{\circ}$, with an estimated distance, $\mathrm{o}^{\prime \prime} 45$, and the intermediate measures by Baron Dembowski, in 1866, confirm the change in angle and distance. A great change is remarked in $\Sigma 651$; at the epoch $1829: 67$ we have, position IOI $I^{\circ} 8$, distance $10^{\prime \prime} \cdot 82$, whereas the Rugby measures give for $1875^{\circ} 18$, position $59^{\circ} 3$, distance $16^{\prime \prime} 26$. In this case it is probable that the alteration is caused by proper motion of one of the components: thus the measures may be reconciled, if we suppose an annual motion of the principal star of about $0^{\prime \prime} \cdot 243$ in the direction $17^{\circ} \cdot 9$. Of 32 Orionis it is remarked "not divided, perhaps binary," and the angle for $1874^{\circ} \mathrm{I}$ is $198^{\circ} .5$; between 1830 and 1853 the distance appears to have been about one second without any decided change in the position, which by a mean of Struve, Dawes, and Jacob was $203^{\circ} 6$; the star seems to require further attention. Of 33 Pegasi, another object measured at Rugby, Struve remarks "comes in cœlo prorsus quiescit," or in other words the change in angle and distance noted between his measures in 1829 and 1851 , is due to the proper motion of the principal star, which, according to Madler, amounts to $34^{\prime \prime} \circ$ in the century, in the direction $93^{\circ} 5$. Mr. Wilson's measures of O.乏. 3 II confirm the marked diminution of distance 